\title{
The Research on the Relationship between Task-based Language Teaching and Listening Motivation of English Majors
}

\author{
Chunyan Chen
}

Foreign Languages School, Jingchu University of Technology, Jingmen, Hubei, China

Keywords: Task-based language teaching; Listening motivation; Interest; Self-efficiency; Anxiety

\begin{abstract}
A deep research is done on the relationship between task-based language teaching and listening motivation of English majors. The aims of this study are as follows: Firstly, it is to verify whether TBLT is conducive to improving students' motivation of listening and listening achievement. Secondly, it is to find the effects of TBLT on the motivation of students of different language proficiency levels are different. Thirdly, the aim is to explore how TBLT influences students' English learning motivation. The result of the study yields the following findings:

TBLT is conducive to improving students' listening proficiency to a certain extent. The students in EG got evident improvement in CET4 tests.

The effects of TBLT on the motivation of students of different levels are different. Students of high and medium level performed better than students of low level. While, the motivation of students in medium level group was promoted to the largest extent.

TBLT is conducive to improving students' motivation of listening and students' motivation is enhanced in terms of higher interest and self-efficiency, lower anxiety, and highlighting of value and goal in TBLT.

The essay illustrates the promotion of students' motivation which guides the English listening teaching in college.
\end{abstract}

\section{Introduction}

Recently, English learning is gaining popularity among the young and old in china. Task-based Language Teaching is an offshoot of Communicative Language Teaching. Task-based Language Teaching advocates the use of communicative tasks in English class. According to David Nunan (1989), TBLT has three characteristics. The first characteristic is learning communication through interaction in the target language. The second is the introduction of authentic texts into the learning situation. The third characteristic is the provision of opportunities for learners to focus, not only on language, but also on the learning process itself [1]. TBLT's initial form derives from Second Language Acquisition (SLA) research. Lightbown and Spada (2001: 38 ) regards successful acquisition as being very bound up with the nature of the language input that the students receive [2]. Krashen thought students master language only by comprehensible input. If the comprehensible input, to a certain extent, surpasses student's current language level, language acquisition will naturally take place. That is 1 plus 1 hypothesis. Based on this theory, Krashen proposed the input hypothesis[3]. Thus, in TBLT, teachers should provide adequate authentic language and materials in class in pursuit of students' full exposure to the target language.

Paget(1974:29-37) as a typical representative of cognitive psychology thought that Learners' learning is consistent with each one's cognitive ability, which attaches great importance to the constructive nature of the learning process[4].

Many researchers in TBLT have been conducted to do research on the relationship between the implications and its effects. Some scholars (Prabhu, 1987: Skehan, 1998) investigate the factors affecting task difficulty and examine how task conditions affect learners' mastery of language in oral and written form[5]. However, most researches are focused on the teaching of grammar and teacher's training. In terms of application of TBLT into the teaching of listening, Willis (1996) [6] provided theoretical supporting to implication of TBLT to listening teaching, but the above relevant research is theoretical. In China, there is little empirical study of TBLT applied to the English listening in colleges. 
The first creation of this thesis is the research on the relationship between motivation and some kind of teaching method, TBLT. The second highlight is the research subject concentrating on three levels of a class, instead on the whole class, which most previous research focuses on.

\section{The Research Methods}

The Subject of Study. The experimental study was conducted in Jingchu College of technology in Hubei province on the basis of supporting theories of TBLT. And 70 sophomores of English majors in Jingchu College of technology participated in this study. They are from two intact classes randomly assigned as experimental class with 34 students and control class with 36 students. For control class, researcher implemented the normal teaching schedule of Jingchu College of technology in abiding by the normal plan. The two classes use the same book, listen this way, complied by Higher Education Press. Each class receives two classes a week for listening, and each class lasts for forty-five minutes.

Research Methods and Means. This study combines quantitative and qualitative methods, and gains data through the empirical study and interview. The research is based on the empirical study and adopts pretest-posttest control group design to testify whether TBLT has an influential impact on students' listening achievement, consisting of pretest, treatment and posttest. CET 4 in June, 2015 is used as the pretest before experiment. CET 4 in December, 2015 is used as posttest after 14-week experiment. Besides pretest and posttest, a motivation scale is also adopted in this essay to measure students' motivation directly. The same motivation scale is implied before and after experiment so as to confirm whether TBLT enhances students' motivation in a direct way. Participants by random classes receive conventional instruction or TBLT in English listening for a period of 14 weeks. Before and after 14 weeks, pretest and posttest are implemented. In order to confirm whether TBLT affects students' listening motivation and explore in what way TBLT influences motivation, a questionnaire is designed and applied before and after experiment. In order to confirm whether TBLT affects students' listening motivation and explore in what way TBLT influences motivation, a questionnaire is designed and applied before and after experiment.

At the end of the experiments, students in both EG and CG finished a post-questionnaire to compare the emotional changes and motivation changes after they received different listening teaching approaches for 14 weeks.

At last, the students from different groups would get an interview by the researcher to see if their English listening comprehension level and motivation of listening have been improved or not under TBLT approach, and which group students have made the greatest progress in both English listening comprehension level and learning motivation in TBLT.

Data collected from the results of questionnaires, English learning motivation scale and two tests (pre-test and post-test) of the listening comprehension are analyzed and discussed on the statistical analysis. All the collected data are put into the computer and analyzed by the authoritative software SPSS.

\section{Data Analysis and Discussion}

Data Analysis of the Pretest and Posttest and Discussion. Before experiment, the mean score of EG and CG is separately 15.24 and 16.87 , with a full score are 35 . The mean score is 1.63 point lower than that of the CG and sig ( 2-tailed) is 0.187 (>0.05). That shows that there is little difference in the EG and in the CG on their English listening Proficiency and the proceeding statistical analysis is meaningful. After 14 weeks of experiment, the following is the analysis of the post-experimental test in the EG and CG. 
Table 1 Independent sample test of students' scores in the post-test

\begin{tabular}{ccclcl}
\hline Group & $\mathrm{N}$ & Mean & $\begin{array}{l}\text { Std. } \\
\text { Deviation }\end{array}$ & $\begin{array}{l}\text { Std. Error } \\
\text { Mean }\end{array}$ & $\begin{array}{l}\text { Sig } \\
\text { (2-tailed) }\end{array}$ \\
\hline EG & 34 & 18.67 & 4.102 & .894 & 0.033 \\
CG & 36 & 17.64 & 4.121 & .854 & \\
\hline
\end{tabular}

From the comparison of two groups, as it is showed in Table1, after experiment there is remarkable difference between the EC and the CC. For the EG, the mean is 18.67; for the CG, the mean is 17.64, and in the independent sample test of post-experimental test, the sig (2-tailed) is 0.033, which is less than 0.05.The mean of the two class has increased, which means that both two classes have made progress after a semester.

From table, we can see that Sig. $(2$-tailed $)=.000 \mathrm{P}<0.05$. It implies that students in EG showed significant difference between pretest and posttest in their English listening proficiency. While the mean score of the CG has almost stayed the same (from 16.87 to17.64, the sig(2-tailed) is $0.334>0.05)$. Therefore, it might be safe to say that the overall English level of the EG has been greatly promoted because of the application of TBLT. In order to make further comparison of learning effect in EG and CG, comparison of Std. Deviation is made. Std. Deviation of EG (4.973) is higher than that of CG (4.223) in the pre-experimental test, while Std. Deviation of EG( 4.102) is lower than that of $\mathrm{CG}(4.121)$ in the post-experimental test, which indicates that TBLT has a positive effect on learners' listening achievement.

The hypothesis 1 can be verified that TBLT is conducive to improving students' listening proficiency effectively according to the above analysis of pretest and posttest data.

The following is the result of it before experiment.

Table 2 Motivation scores in the EG and CG before experiment

\begin{tabular}{llllll}
\hline Score & Level of motivation & $\mathrm{N}$ & $\begin{array}{c}\text { CG } \\
\text { Percentage }\end{array}$ & $\mathrm{N}$ & $\begin{array}{c}\text { EG } \\
\text { Percentage }\end{array}$ \\
\hline $19-26$ & High & 9 & $25 \%$ & 8 & $24 \%$ \\
$9-18$ & Middle & 15 & $42 \%$ & 14 & $41 \%$ \\
$9-0$ & low & 12 & $33 \%$ & 12 & $35 \%$ \\
\hline
\end{tabular}

It can be drawn that the motivation of students in two groups is nearly the same

Analysis of Motivation Scale and Discussion. The following is the result of it after experiment.

Table 3 Motivation scores in the EG and CG after experiment

\begin{tabular}{lllllc}
\hline Score & Level of motivation & $\mathrm{N}$ & $\begin{array}{c}\text { CG } \\
\text { Percentage }\end{array}$ & $\mathrm{N}$ & $\begin{array}{c}\text { EG } \\
\text { Percentage }\end{array}$ \\
\hline $19-26$ & High & 10 & $28 \%$ & 14 & $42 \%$ \\
$9-18$ & Middle & 13 & $36 \%$ & 15 & $44 \%$ \\
$9-0$ & low & 13 & $36 \%$ & 5 & $14 \%$ \\
\hline
\end{tabular}

From the above table, it can be easily drawn that students' motivation in EG is greatly promoted. While, there is no obvious change of scores of motivation scale in CG. The number of students of middle scale motivation has declined by $6 \%$, while the low has increased by $1 \%$. The main independent variable in EG and CG is teaching approach.

The self-efficiency becomes low for students in CG. They may not make effort in listening as they don't believe they can do well in class. While, in TBLT class, the teacher provides a lot of 
pictures of video clips to arouse students' interest in class in pre-task, students have the desire to concentrate on class. The activities in pre-task reduce the difficulty of listening tasks, which demonstrates Scaffolding principle.

The following is the analysis of the motivation increase in three groups of EG.

Table 4 Motivation comparison in the EG

\begin{tabular}{lll}
\hline & N & Mean \\
\hline Group 1 & 11 & 3 \\
Group 2 & 11 & 6 \\
Group 3 & 11 & 1 \\
\hline
\end{tabular}

From table 4, we can conclude that the motivation of students of high and medium proficiency level is higher than students of low level. While, the motivation of students of medium proficiency level was promoted to the largest extent. According to the previous research, it is universally accepted that the intrinsic motivation is the long-lasting motivation and students make more effort in learning.

According to Goal theory, Locke and Latham's (2002) asserts that human action is caused by purpose, and for action to take place; goals have to be set and pursued by choice[7]. Setting an appropriate goal plays an important role in motivation and as a result the decision can be carried out and the required effort maintained. For students of high level, their goals have already set. It is not so significant for students of high level to set a goal in TBLT class as students of medium and low level. To such extent, students' motivation caused by goal can not be promoted to a large extent.

\section{Results of the Interview.}

At the end of the interview, 3 points were categorized from the results of the interview according to the question.

Question 1: Do you have any different opinions on listening class this semester compared with last semester?

Answers from students in CG: there is not any difference in listening. Answers from students in EG: They are looking forward to having listening class now; English listening is more interested than before as activities in class are very meaningful. students in CG feel they have the same feeling as before. While students in EG demonstrate a few changes. The three items of change are concerned with learning motivation, including learning desire, interest, making effort.

Question 2: Do you like the present listening class? Why or why not?

Answers from students in CG: most of them do not like listening class as it is boring and they feel frustrated. The activity is nearly the same.

Answers from students in EG: most of them like listening class, and there are a few reasons. Firstly, TBLT is effective in improving subjects' communicative skills. Secondly, pre-task phases reduce students' anxiety and arouse their interest. Thirdly, cooperative activities promote language learning. TBLT embodies the principles of authenticity. Authentic listening material provides students with a natural environment of language learning.

Question 3: What affected your motivation during this term? And how did they affect you?

Answers from students in CG: they show no obvious change in motivation. Answers from students in CG: nearly all the students in EG talked about the new teaching approach which affected their motivation. Because of TBLT, they were interested in TBLT class, became more confident, felt less anxious in the class, and made more effort in listening than before.

Expectancy-value Theory

Dornyei(1998) proposes that motivation to perform various tasks is the product of two key factors: the individual's expectancy of success in a given task, and the value that the individual attaches to success on the basis of the main principles of expectancy-value theories[8]. Expectancy-value theory implies that people determine and do things in the world according to their 
expectations (beliefs) and evaluations.

Self-efficacy Theory

Pajares (1996) reports that self-efficacy could span a range of topics that include addiction, depression, assertiveness and pain control, as well as influencing students' motivation to learn new knowledge[9]. Bandura (1997) hypothesizes that self-efficacy influences choice of activities, effort and persistence[10].

\section{The Suggestions}

\section{To Adopt TBLT in English Listening Teaching}

TBLT is such an effective teaching approach to improve students' listening and enhance students' achievement, so TBLT is highly recommended to be introduced into the students' current curriculum and other teaching fields, such as speaking, reading and writing.

\section{To Motivate Students' Motivation By Designing Task-based Activities}

The first is to reduce their anxiety and improve their self-efficiency by group activities in the pre-task phrase and cooperative learning after class. Students' mental pressures can be reduced by their teachers, such as organizing some activities in pairs or in groups to grade the difficulty of the task. And the cooperative activities facilitate meaning negotiation and reduce difficulty of the task and improve their self-efficiency. The second is to highlight the objective in each task in order to obtain the effectiveness of learning in the process of completing tasks; the objective of tasks should be emphasized at the beginning of each task. The third is to increase the students' desire for learning by making the tasks interesting and authentic. The forth is that teachers should show more concern for students of low proficiency level. The last one is that teachers should improve themselves in both language proficiency and communicative skills.

\section{Conclusion}

TBLT is conducive to improving students' listening proficiency effectively. There is no other independent variable in two groups, except for teaching approach. Students in EG demonstrated great difference between pretest and posttest in their English listening proficiency, while students in CG demonstrated no significant difference between pretest and posttest, according to the comparison between the students' scores in the pretest and posttest. Thus, the students' listening proficiency is improved by TBLT.

The effects of TBLT on the listening of students of different proficiency level are different. The data analysis showed that students of high and medium proficiency level performed better than students of low level. While, the motivation of students of medium level was promoted the most.

TBLT is conducive to improving students' motivation of listening. TBLT improves learners' self-efficiency, arouses the learner' interest in language learning, and highlights the goal in each task and reduces learners' anxiety.

\section{References}

[1] Nunan, D. Designing Tasks for the Communicative Classroom [M]. Cambridge: Cambridge University Press, 1989.

[2] Lightbown Spada. How language are learned [M]. Shanghai: Shanghai Foreign Language Teaching and Research Press, 2001.

[3] Krashen, S. D. Principles and Practice in Second Language Acquisition. NJ: Prentice-Hall International (UK) Ltd, 1985.

[4] Piaget, J. The Child's Conception of the World [M]. NewYork: Littlefield, 1990.

[5] Prabhu, N. S. Second Language Pedagogy [M]. Oxford: Oxford University Press, 1982.

[6] Willis, J. A Framework for Task-based Learning [M]. London: Longman. 1996.1

[7] Locke, E.A \& Latham, G. P. Building a practically useful theory of goal setting and task motivation: A 35-year odyssey [J]. American Psychology,2002(36), 311-329 
[8] Dornyei, $\mathrm{Z}$.Motivation in Second and Foreign Language Learning [J]. Language Teaching,1998 (31): 117-135.

[9] Pajares, F. Self-efficacy beliefs in academic settings [J]. Review of Educational Research, 1996(66), 543-578.

[10] Bandura, A. Self-efficacy: the exercise of control [M]. New York: WH Freeman,1997. 